\title{
Incidence and functional outcome of atrial fibrillation and non-atrial fibrillation- related cardioembolic stroke in Joinville, Brazil: a population-based study
}

Incidência e desfecho funcional de AVC cardioembólico com e sem fibrilação atrial em Joinville, Brazil: estudo de base populacional

Claudio Henrique do Amaral',2, Augusto R. Amaral', Vivian Nagel², Vanessa Venancio², Adriana Coronetti Garcia², Pedro SC Magalhaes ${ }^{2,3}$, Alexandre L Longo ${ }^{3}$, Carla HC Moro ${ }^{3}$, Felipe I Reis ${ }^{2}$, Andre D’Avila', Norberto L Cabral ${ }^{1,2}$

\begin{abstract}
Among ischemic strokes, cardioembolic (CE) stroke has the worst outcome. We measured the incidence of atrial fibrillation (AF) and non-AF related CE strokes, previous anticoagulant use, and the 90-day functional outcome. Using multiple overlapping sources, we included all CE strokes that occurred in 2015 in Joinville, Brazil. Of the 374 ischemic strokes, 23\% (84) were CE. The CE age-adjusted incidence, per 1,000 person-years, was 0.14 (0.11-0.17). Of the 26 patients with known prior AF, 73\% (19) were not anticoagulated, 77\% (20) had a CHA $\mathrm{DS}_{2} V A S c$ score $\geq 3$ and $81 \%$ (21) had a HAS-BLED score<3. After three months, approximately one third of those 26 patients died or became disabled. The incidence of CE stroke in our sample was lower than in other population-based studies. The opportunity for anticoagulation was missed in one third of cases.
\end{abstract}

Keywords: stroke; incidence; prognosis; population studies in public health.

RESUMO

Entre todos os subtipos de AVC isquêmico, os eventos cardioembólicos (CE) apresentam os piores prognósticos. Determinamos a incidência de AVC isquêmico CE, associada ou não à fibrilação atrial (FA), o uso prévio de anticoagulantes e os desfechos funcionais em Joinville, Brasil. Utilizando múltiplas e sobrepostas fontes de informação, registramos todos os primeiros eventos CE ocorridos em 2015 . Entre 374 eventos isquêmicos, 23\% (84) foram CE. A incidência ajustada, para qualquer fonte cardioembólica, foi 0.14 (0.11-0.17) por 1000 pessoas-ano. Entre 26 pacientes com FA previamente conhecida, 73\% (19) não estavam anticoagulados, 77\% (20) tinham $\geq 3$ pontos na escala $\mathrm{CHA}_{2} \mathrm{DS}_{2}$ VASc e $81 \%$ (21) < 3 pontos na escala HAS-BLED. Após 3 meses, um terço destes 26 pacientes morreram ou ficaram dependentes. A incidência de AVC I CE em Joinville é menor do que em outros estudos de base populacional. Um terço dos casos de AVC I CE com FA previamente conhecida perderam a oportunidade de anticoagulação.

Palavras-chave: acidente cerebral vascular; incidência; prognóstico; estudos populacionais em saúde pública.

Worldwide, ischemic stroke is the most common major pathological type of stroke ${ }^{1}$. Among all ischemic stroke subtypes, cardioembolic (CE) stroke is particularly worrisome for two main reasons. The first one is demographic: as age is a risk factor for both atrial fibrillation (AF) and stroke, the aging of the population will progressively increase the burden of CE stroke in many countries. ${ }^{1,2}$ The second reason involves outcomes: in a population-based study in Oxfordshire, UK, 2,555 ischemic stroke subtypes were followed up from 2002 to 2014. After six months, two thirds were dependent. After one year, $42 \%$ had died. These outcomes are significantly higher than those reported for other ischemic stroke subtypes ${ }^{2}$.

Therefore, knowing the incidence of $\mathrm{CE}$ stroke is crucial for primary and secondary prevention policies ${ }^{1,2,3}$.

\footnotetext{
'Universidade da Região de Joinville, Joinville SC, Brasil;

${ }^{2}$ Registro de AVC de Joinville, Joinville SC, Brasil;

${ }^{3}$ Clinica Neurologica de Joinville, Joinville SC, Brasil;

4Hospital SOS Cardio, Florianópolis SC, BRasil.

Correspondence: Norberto L Cabral; Rua Plácido O. Oliveira, 1244; 89201-165 Joinville SC, Brasil; E-mail: norbertocabral@icloud.com

Conflict of interest: There is no conflict of interest to declare.

Received 16 June 2016; Received in final form 17 December 2016; Accepted 03 February 2017.
} 
The age-adjusted incidence of CE stroke ranges from 17 to 40 per 100,000 person-years ${ }^{4,5}$. As the prevalence of AF increases, due partly to the aging population ${ }^{6}$, we would expect more AF-related CE strokes in the future ${ }^{7}$.

The Global Burden of Diseases Study Group showed that, from 1990 to $2013,75 \%$ of deaths from strokes and $81 \%$ of the stroke-related disability-adjusted life years lost occur in lowand middle-income countries ${ }^{8}$, where the progressive economic pressure of the growing elderly population is occurring ${ }^{9}$. However, little epidemiological data on CE stroke are available from those countries. To address this knowledge gap, we aimed to measure the incidence of AF-related and non-AF-related CE stroke, the stroke risk stratification scale distribution ( $\mathrm{CHA}_{2} \mathrm{DS}_{2}$ VASc) and 90-day modified Rankin scale proportions in Joinville, Brazil.

\section{METHODS}

\section{The Joinville population registry}

Joinville is a city in southern Brazil of $1,130 \mathrm{~km}^{2}$ and with 516,288 inhabitants, according to the last national census in $2010^{10}$. The city has four hospitals (one with a stroke unit) and one public institutional care facility. The Joinville Stroke Registry is an ongoing population-based stroke data bank, which started in 2005, and has been supported by law since $2013^{11}$. The methods for stroke ascertainment in our registry have previously been published ${ }^{12}$. In brief, we used multiple overlapping sources of ascertainment according to the World Health Organization STEPS criteria ${ }^{13}$.

\section{Cohort sample}

Over one year (April 2014 to March 2015), we included all patients with a first-ever ischemic stroke. We also included residents in the city with a confirmed stroke that occurred outside of the city limits. Patients with transient ischemic attacks were not included. We excluded stroke cases in which the patient died within the first 24 hours of symptom onset without a brain CT and no reliable medical record, as well as patients residing outside of the Joinville city limits.

\section{Routine data collection}

We obtained demographic, cardiovascular risk factor, biochemical, electrocardiographic (ECG) and radiological tests. All patients underwent at least one brain CT and transthoracic echocardiogram. Stroke diagnosis followed established diagnostic criteria $^{1,12,14}$. The pathophysiological diagnosis of stroke was based on the criteria described in the Trial of ORG 10127 in the Acute Stroke Treatment (TOAST) study ${ }^{15}$. The stroke investigation routine followed the guidelines of the Brazilian Society of Cerebrovascular Diseases ${ }^{16}$. The Brazilian Economic Classification Criterion was the instrument chosen to evaluate the patients' economic class ${ }^{17}$. To calculate stroke risk in patients with $\mathrm{AF}$, we used the $\mathrm{CHA}_{2} \mathrm{DS}_{2} \mathrm{VASc}$ score $^{18}$. To calculate the risk of bleeding on anticoagulation, we used the HAS-BLED score ${ }^{19}$.

\section{Cardioembolic diagnostic work-up}

Holter monitoring was ordered in patients whose medical histories and physical examinations suggested a cardiac source of embolism and in patients with a cryptogenic diagnostic work-up. The ECGs with AF were classified as chronic, new or paroxystic. Chronic AF (known previously) included cases of long-standing AF confirmed by ECG (e.g., greater than one year), in which cardioversion was not indicated or attempted, usually leading to permanent $\mathrm{AF}^{20}$. When a patient had two or more episodes, AF was considered recurrent. When it spontaneously returned to sinus rhythm, AF was designated paroxysmal, and when it was sustained, $\mathrm{AF}$ was designated as new. In the latter case, termination by pharmacological therapy or electrical cardioversion did not change the designation ${ }^{20}$. In the hospitals, we asked about previous anticoagulant use and checked the intensity of anticoagulation against the International Normalized Ratio (INR) value. We registered the type of anticoagulant prescription at hospital discharge.

\section{Evaluation of outcomes}

Functional independence was evaluated using the modified Rankin scale (mRS), which ranges from 0 (no symptoms) to 6 (death $)^{21}$. The mRS scores were assessed at one month (face-to-face) and at 90 days (by telephone) by interviewers who were blinded to the patient groups.

\section{Statistical analysis}

To calculate incidences and 95\% confidence intervals (CI), we used the Poisson distribution for the number of events. We calculated the crude incidence rates for 2014-2015 as (total event cases)/(total population at risk). The population-at-risk data were extracted from the national census and from the last intercensal data ${ }^{10}$. Incidence was adjusted for age by the direct method using both the 2010 census population of Brazil and the SEGI “world” population as standards ${ }^{22}$. This study was approved by the Ethics in Research Committees.

\section{RESULTS}

From April 2014 to March 2015, we registered 429 patients with any type of first-ever stroke in Joinville. Of those, $87.2 \%$ (374/429) were ischemic strokes, 7.5\% (32/429) were haemorrhagic stroke and 5.4\% (23/429) were subarachnoid haemorrhage. Among the ischemic strokes, 26.5\% (99/374) were smallvessel disease, $23.3 \%$ (87/374) were large-vessel disease, $22.5 \%$ (84/374) were CE, $15.2 \%$ (57/374) were undetermined and $12.6 \%$ (47/374) were other determined subtypes. The proportion of any type of AF among all ischemic stroke events was 11.4\% (49/429), and $58.3 \%$ (49/84) of all CE strokes were AF-related. 
Table 1 compares the demographic and clinical risk factor findings between 49 patients with AF-related and 35 patients with non-AF-related CE stroke. We found that patients with $\mathrm{AF}$-related events were older than patients with non-AF ( $p<0.001$ ), had a slightly higher prevalence of hypertension $(p=0.05)$ and a lower prevalence of smoking habits $(\mathrm{p}<0.01)$. As expected, the median on the HAS-BLED scale was higher in AF-related events $(\mathrm{p}=0.01)$. Of the 26 patients who arrived in emergency departments with known prior AF, seven were using anticoagulants (four on warfarin, two on rivaroxaban, and one on dabigatran). Among those, $20(76.9 \%)$ had a $\mathrm{CHA}_{2} \mathrm{DS}_{2}$ VASc score $\geq 3$, and $21(80.8 \%)$ had a HAS-BLED score $<3$. Of the four patients who were using warfarin, three had INR levels below the target, and the level was not determined for the last one.
Data are number of patients (\%) unless otherwise indicated. Social class per Brazilian Criteria of Economic Classification based on 2013 National Household Sample Survey. Amounts per year in US dollars. Class: A = 64,020; B1 = 27,468; B2 = 19,980; $\mathrm{C} 1=8,256$; $\mathrm{C} 2=4,572$; D-E: 2,016. The Brazilian gross domestic product per capita at purchasing power parity per the World Bank in 2013 was US\$14,997 per year in 2013. AF: atrial fibrillation; MI: myocardial infarction; CHF: chronic heart failure; BMI: body mass index; SD: standard deviation; NIHSS: National Institute of Health stroke scale.

The crude and age-adjusted incidences per 1,000 person-years of first-ever AF-related and non-AF-related events are shown in Table 2. The incidence per 1,000 patient-years, age-adjusted to theworld population, was 0.10(95\% CI,0.07-0.13)

Table 1. Demographic, socio-economic and cardiovascular risk factors of patients with AF and non-AF-related cardioembolic ischemic stroke.

\begin{tabular}{|c|c|c|c|c|}
\hline Variable & $A F(n=49)$ & Non-AF $(n=35)$ & All CE $(n=84)$ & $p$-value \\
\hline \multicolumn{5}{|l|}{ Demographic } \\
\hline Men (SD) & 19 (37.0) & 19 (54.3) & $38(45.2)$ & 18 \\
\hline Mean age (SD) & $77.0(10.5)$ & $62.0(14.4)$ & $71.0(14.2)$ & $<0.001$ \\
\hline \multicolumn{5}{|l|}{ Education (years) } \\
\hline Illiterate or $<3$ years & $20(40.8)$ & $9(25.7)$ & $29(34.5)$ & 0.84 \\
\hline 4 years & $21(42.9)$ & $8(22.9)$ & $29(34.5)$ & \\
\hline 8 years & $4(8.2)$ & $6(17.1)$ & $10(11.9)$ & \\
\hline 11 years & $2(4.1)$ & $8(22.9)$ & $10(11.9)$ & \\
\hline$>11$ years & $1(2.0)$ & $3(8.6)$ & $4(4.8)$ & \\
\hline \multicolumn{5}{|l|}{ Social class* } \\
\hline A1 & $0(0.0)$ & $0(0.0)$ & $0(0.0)$ & 1.0 \\
\hline $\mathrm{A} 2$ & $0(0.0)$ & $2(5.7)$ & $2(2.4)$ & \\
\hline B1 & $1(2.0)$ & $2(5.7)$ & $3(3.6)$ & \\
\hline B2 & $8(16.2)$ & $10(28.6)$ & $18(21.4)$ & \\
\hline $\mathrm{C} 1$ & $23(46.9)$ & $11(31.4)$ & $34(40.5)$ & \\
\hline $\mathrm{C} 2$ & $10(20.4)$ & $7(20.0)$ & $17(20.2)$ & \\
\hline $\mathrm{D}$ & $5(10.2)$ & $3(8.6)$ & $8(9.5)$ & \\
\hline$E$ & $1(2.0)$ & $0(0.0)$ & $1(1.2)$ & \\
\hline \multicolumn{5}{|l|}{ Cardiovascular risk factors } \\
\hline Hypertension & $39(79.6)$ & $21(60.0)$ & $60(714)$ & 0.05 \\
\hline Diabetes mellitus & $19(38.8)$ & $12(34.3)$ & $31(36.9)$ & 0.67 \\
\hline Dyslipidaemia & $32(65.3)$ & $23(65.7)$ & $55(65.5)$ & 0.96 \\
\hline Current smoker & $3(6.1)$ & $9(25.7)$ & $12(14.3)$ & 0.01 \\
\hline Ex-smoker & $14(28.6)$ & $12(34.3)$ & $26(31.0)$ & 0.57 \\
\hline Never smoked & $32(65.3)$ & $14(40.0)$ & $46(54.8)$ & 0.02 \\
\hline MI & $0(0.0)$ & $2(5.7)$ & $2(2.4)$ & 0.17 \\
\hline $\mathrm{CHF}$ & $14(28.6)$ & 17(48.6) & $31(36.9)$ & 0.06 \\
\hline Vascular claudication & $11(22.4)$ & $6(17.1)$ & $11(20.2)$ & 0.55 \\
\hline Alcoholism & $3(6.1)$ & $10(28.6)$ & $8(9.5)$ & 0.27 \\
\hline $\mathrm{BMI}>30$ & $11(22.4)$ & $14(40.0)$ & $25(29.8)$ & 0.08 \\
\hline \multicolumn{5}{|c|}{ Stroke severity and stroke prediction scales } \\
\hline NIHSS at admission & 6 & 4 & 5 & 0.59 \\
\hline $\mathrm{CHA}_{2} \mathrm{DS}_{2}-\mathrm{VASc}$ (median) & 4 & & & \\
\hline HAS-BLED (median) & 2 & 1 & 1.5 & 0.01 \\
\hline
\end{tabular}


Table 2. Incidence rates of first-ever AF and non-AF-related cardioembolic ischemic stroke in Joinville, Brazil, in 2015.

\begin{tabular}{|c|c|c|c|}
\hline \multirow{2}{*}{ Variable } & Men & Women & Total population \\
\hline & Incidence $(95 \% \mathrm{Cl})$ & Incidence $(95 \% \mathrm{Cl})$ & Incidence $(95 \% \mathrm{Cl})$ \\
\hline \multicolumn{4}{|l|}{ AF-related CE } \\
\hline \multicolumn{4}{|l|}{ Age (years) } \\
\hline$<55$ & - & $0.01(0.002-0.04)$ & $0.016(0.007-0.03)$ \\
\hline $55-64$ & $0.26(0.08-0.6)$ & $0.09(0.01-0.34)$ & $0.17(0.07-0.35)$ \\
\hline $65-74$ & $0.60(0.2-1.40)$ & $0.48(0.15-1.11)$ & $0.53(0.26-0.98)$ \\
\hline $75-79$ & $1.42(0.29-4.16)$ & $1.23(0.34-3.14)$ & $1.31(0.52-2.69)$ \\
\hline$\geq 80$ & $3.25(1.2-7.1)$ & $4.79(2.83-7.57)$ & $4.28(2.74-6.37)$ \\
\hline Total & $0.07(0.04-0.11)$ & $0.11(0.08-0.16)$ & $0.09(0.07-0.12)$ \\
\hline Adjusted Brazil ${ }^{\star}$ & - & - & $0.08(0.06-0.11)$ \\
\hline Adjusted World ${ }^{\dagger}$ & - & - & $0.10(0.07-0.13)$ \\
\hline \multicolumn{4}{|l|}{ Non-AF-related CE } \\
\hline \multicolumn{4}{|l|}{ Age (years) } \\
\hline$<55$ & $0.12(0.04-0.29)$ & $0.11(0.03-0.28)$ & $0.12(0.05-0.22)$ \\
\hline $55-64$ & $0.47(0.21-0.88)$ & $0.23(0.07-0.55)$ & $0.34(0.19-0.58)$ \\
\hline $65-74$ & $0.12(00.2-0.67)$ & $0.19(0.02-0.69)$ & $0.16(0.03-0.47)$ \\
\hline $75-79$ & $1.42(0.29-4.16)$ & - & $0.56(0.11-1.63)$ \\
\hline$\geq 80$ & $0.54(0.01-3.02)$ & $1.33(0.43-3.10)$ & 1.07 (0.39-2.33) \\
\hline Total & $0.07(0.04-0.11)$ & $0.06(0.03-0.10)$ & $0.07(0.05-0.09)$ \\
\hline Adjusted Brazil* & - & - & $0.05(0.04-0.08)$ \\
\hline Adjusted World ${ }^{\dagger}$ & - & - & $0.07(0.05-0.1)$ \\
\hline \multicolumn{4}{|l|}{ All causes of CE } \\
\hline \multicolumn{4}{|l|}{ Age (years) } \\
\hline$<55$ & $0.12(0.04-0.29)$ & $0.14(0.05-0.32)$ & $0.13(0.06-0.23)$ \\
\hline $55-64$ & $0.72(0.40-1.21)$ & $0.33(0.13-0.68)$ & $0.52(0.32-0.80)$ \\
\hline $65-74$ & $0.72(0.26-1.56)$ & $0.67(0.27-1.38)$ & $0.67(0.37-1.18)$ \\
\hline $75-79$ & $2.85(1.04-6.19)$ & $1.23(0.34-3.14)$ & $1.86(0.89-3.43)$ \\
\hline$\geq 80$ & $3.79(1.52-7.81)$ & $6.12(3.88-9.18)$ & $5.35(3.61-7.64)$ \\
\hline Total & $0.14(0.10-0.20)$ & $0.17(0.12-0.23)$ & $0.16(0.13-0.20)$ \\
\hline Adjusted Brazil ${ }^{\star}$ & - & - & $0.16(0.13-0.20)$ \\
\hline Adjusted World ${ }^{\dagger}$ & - & - & $0.14(0.11-0.17)$ \\
\hline
\end{tabular}

Rates per 1000 inhabitants * Adjusted by direct method to Brazilian population per the 2000 census; $†$ Segi's world population. AF: atrial fibrillation CE: cardioembolic stroke

for AF-related events, 0.07 (0.05-0.1) for non-AF-related events, and $0.14(0.11-0.17)$ for all causes of CE stroke events. Incidence rates of $\mathrm{AF}$ and non- $\mathrm{AF}$ events were similar in men and women. In those over 80 years old, 24/49 (49\%) occurred in AF-related patients, and only 6/35 (17.1\%) occurred in non-AF-related patients. Among patients with AF-related events, the proportion increased progressively with age, ranging from $2 \%$ at $<55$ years to $63 \%$ at $>75$ years. On the contrary, among patients with non-AF-related events, $40 \%$ occurred at age $55-64$ years and $26 \%$ at age $>75$ years.

The diagnostic work-up of $\mathrm{CE}$ patients is shown in Table 3. In patients with AF-related events, 26/49 (53\%) were chronic AF (known previously), 15/49 (30\%) were paroxysmal AF and 6/49 (12\%) were new AF. A 24-hour Holter monitoring period was carried out in 6/49 (12.2\%) of the AF-related events and in only $1 / 35$ (3\%) of the non-AF-related events (Table 3). No patient had prolonged cardiac monitoring (insertable, or by telemetry). In patients with non-AF events, $11 / 35$ (31.4\%) had dilated myocardiopathy, and 7/35 (20\%) had chronic heart failure (Table 4).

The Figure shows functional outcomes. The 90-day outcomes were similar in both groups: $40 \%$ became dependent or died. Among AF-related events, four patients changed their address, and among non-AF-related events, we missed one patient. Worryingly, of 23 patients with known prior AF at hospital admission, who were followed for up to three months, two became dependent (mRankin of 3 to 5), and five died (mRankin of 6).

At hospital discharge, 37/49 (75\%) with AF-related CE stroke were on anticoagulant prescriptions. Warfarin was more often indicated than the new anticoagulants (Table 5). Anticoagulant prescription was less indicated in non-AF-related CE stroke than in AF-related CE stroke $(18 / 35$ [51.4\%] versus $12 / 49$ [24.5\%]; $p=0.01)$. 
Table 3. Diagnostic work-up of atrial fibrillation (AF) and non-AF cardioembolic (CE) ischemic stroke.

\begin{tabular}{lccc}
\hline Variable & AF $(n=49)$ & Non-AF $(n=35)$ & All CE $(n=84)$ \\
\hline Cranial tomography & $49(100)$ & $35(100)$ & $84(100)$ \\
Brain magnetic resonance & $9(18.4)$ & $2(2.7)$ & $11(13.1)$ \\
\hline Electrocardiogram & $49(100)$ & $35(100)$ & $84(100)$ \\
$\quad$ Chronic AF & $26(53)$ & - & $26(30.9)$ \\
$\quad$ Paroxistic AF & $15(30.6)$ & - & $15(17.8)$ \\
$\quad$ New AF & $6(12.2)$ & - & $6(7.1)$ \\
$\quad$ Atrial flutter & $2(4)$ & $1(2.9)$ & $2(2.3)$ \\
\hline 24-h Holter & $6(12.2)$ & $35(100)$ & $7(8.3)$ \\
\hline Transthoracic echocardiogram & $49(100)$ & $3(8.6)$ & $84(100)$ \\
\hline Transesophageal echocardiogram & $3(6.1)$ & $27(77.1)$ & $6(7.1)$ \\
Carotid ultrasound & $43(87.8)$ & $19(28.6)$ & $70(83.3)$ \\
Transcranial Doppler & $17(34.7)$ & $0(0)$ & $27(32.1)$ \\
\hline Electroencephalogram & $4(8.2)$ & $1(2.9)$ & $4(4.8)$ \\
Carotid angio-tomography & $1(2)$ & $6(17.1)$ & $2(2.4)$ \\
Carotid angio-MRI & $2(4.1)$ & $0(0)$ & $8(9.5)$ \\
Cerebral angio-MRI & $1(2)$ & $1(1.2)$ & \\
\hline Da & &
\end{tabular}

Data are number of patients (\%) unless otherwise indicated; MRI: magnetic ressonance imaging.

Table 4. Middle and high-risk emboligenic causes in non-atrial fibrillation-related cardioembolic (CE) stroke.

\begin{tabular}{lc}
\hline Non-AF-related CE & $(\mathrm{n}=35)$ \\
\hline High risk & \\
\hline Mechanical valve & $4(11.4)$ \\
\hline Myocardial infarction <4 weeks & $1(2.9)$ \\
\hline Dilated myocardiopathy & $11(31.4)$ \\
\hline Left ventricular akinesia & $3(8.6)$ \\
\hline Atrial myxoma & $2(5.7)$ \\
Medium risk & \\
\hline Mitral ring calcification & $4(11.4)$ \\
\hline Mitral stenosis & $1(2.9)$ \\
\hline FOP & $1(2.9)$ \\
\hline Atrial flutter atrial & $0(0.0)$ \\
\hline Chronic heart failure & $7(20.0)$ \\
\hline Myocardial infarction $>1$ to 6 months & $1(2.9)$ \\
\hline
\end{tabular}

90-day modified Rankin Scale

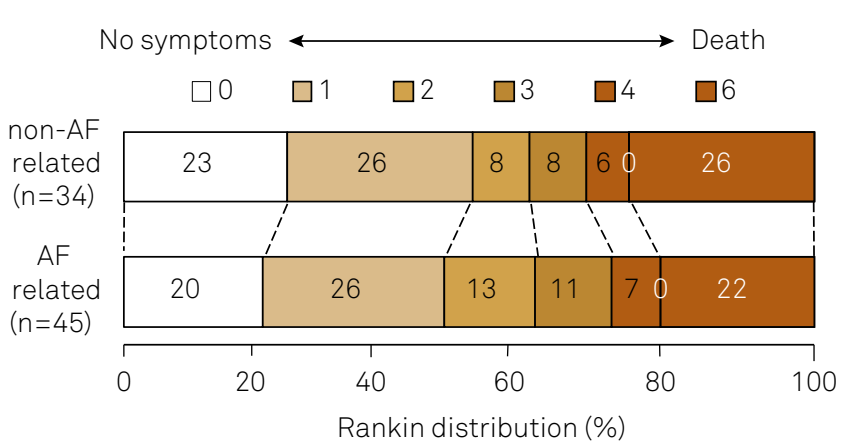

Figure. Modified Rankin scale scores at 90-days between non-AF related and AF related cardioembolic ischemic stroke in Joinville, 2015; AF: atrial fibrillation; 0 to 1: very favorable outcome, 0 to 2: functional independence, 3 to 5: functional dependence and 6: death. Values inside each box were proportions (\%).
Table 5. Anticoagulation prescription at hospital discharge in patients with atrial fibrillation and non-atrial fibrillation cardioembolic ischemic stroke in Joinville, 2015.

\begin{tabular}{lccc}
\hline Anticoagulated & $\mathrm{AF}(\mathrm{n}=49)$ & $\mathrm{Non}-\mathrm{AF}(\mathrm{n}=35)$ & $\mathrm{p}$ - value \\
\hline Warfarin & $26(53.1)$ & $15(42.9)$ & 0.35 \\
Femcoprumon & $1(2.0)$ & $0(0.0)$ & 1.00 \\
Apixaban & $3(6.1)$ & $0(0.0)$ & 0.26 \\
Rivaroxaban & $4(8,2)$ & $0(0.0)$ & 0.13 \\
Dabigatran & $3(6.1)$ & $1(2.9)$ & 0.63 \\
Enoxaparin sodium & $0(0)$ & $1(2.9)$ & 0.41 \\
Not anticoagulated & $12(24.5)$ & $18(51.4)$ & 0.01 \\
\hline
\end{tabular}

\section{DISCUSSION}

The age-adjusted incidence per 1,000 person-years was 0.10 (95\% CI, 0.07-0.13) for AF-related events; 0.07 (0.05-0.1) for non-FA-related events; and 0.14 (0.11-0.17) for all causes of CE stroke events. At hospital discharge, three quarters of AF-related events were on anticoagulant prescriptions, mainly warfarin. After three months, $60 \%$ were functionally independent, $18 \%$ were dependent and $22 \%$ had died. These outcomes were the same for AF-related and non-AF-related events.

Few studies have published the incidence of AF-related stroke specifically. In Dublin, the crude incidence of first-ever AF-associated ischemic stroke was $0.42 / 1000$ person-years $(95 \%$ CI $=0.35-0.51)$ in $2005-2006^{23}$. In Oxford, the crude AF-related incidence was $0.41(0.36-0.45)$ events over 10 years (2002-2012). ${ }^{7}$ These rates are three times higher than our findings. Could these differences be explained by life expectancy? In the UK, for example, 51\% (272/454) of AF-related events occurred in people 80 years or older, whereas in our sample, $35.7 \%$ (30/84) were in the same age 
strata. Distinct socio-economic and ethnic profiles and diagnostic work-up (i.e., proportion of undetermined ischemic strokes) could also explain these diferences ${ }^{1,9,24}$.

Unfortunately, many CE events could have been prevented. The proportion of patients with ischemic stroke and known prior AF who were on premorbid oral anticoagulation were observed in some population-based studies ${ }^{3,7,25}$. In Adelaide, $57 / 81(70 \%)$ of patients with CE events had known previous AF, and 32/57 (56\%) of those were not anticoagulated. ${ }^{3}$ In Oxford, 189/383 (49\%) of AF-related events occurred in non-anticoagulated patients with known prior $\mathrm{AF}^{7}$. In Dublin, $63 / 87(72.4 \%)$ were not on warfarin therapy at stroke onset ${ }^{23}$. In 2000, we reported that 14/21 (66\%) of AF-related events occurred in non-anticoagulated patients with known prior $\mathrm{AF}$ in Joinville ${ }^{26}$. In the current sample, 15 years later, $73 \%(19 / 26)$ with known prior AF were not anticoagulated.

It is interesting to note that three quarters had a previous high risk of stroke on the $\mathrm{CHA}_{2} \mathrm{DS}_{2}$ VASc scale (score $\left.\geq 3\right)^{18}$ although more than three quarters had a low risk of bleeding on the HAS-BLED scale (score $<3)^{19}$. Of concern, a third of these died within three months of becoming disabled. These findings reflect an alarming and sustained poor knowledge of the primary prevention benefits of anticoagulation for AF in our setting, as the use of warfarin or new oral anticoagulants reduces the relative risk of stroke recurrence by $60 \%-70 \% 25$.

The 30-day patient fatality was $22.5 \%$ for AF-related events and $26.5 \%$ for non-AF events. These findings are similar to those reported in Adelaide $(23 \%)^{3}$, Rochester $(30.3 \%)^{27}$ and Iquique $(28 \%)^{28}$. In contrast, the Dublin study reported $23.1 \%$ for AF-related stroke and $12.1 \%$ for non-AF-related stroke ${ }^{23}$.
The major strength of this study is the population-based design $^{12}$. To define the final ischemic stroke subtype (TOAST classification), all CE stroke patients had cranial CT, ECG and echocardiogram; and more than $80 \%$ had carotid ultrasound. The final diagnostics of AF-related and non-AF-related events were double-checked. However, our study has several limitations. It is possible that our CE sample could be underestimated because screening for paroxysmal and new AF events is not ideal. Only $12 \%$ of patients with AF-related events and $3 \%$ of those with non-AF-related events had a 24-hour Holter recording. Less than 10\% had transesophageal ECG. No patient had prolonged cardiac monitoring (insertable or by telemetry). Our registry does not perform "hot pursuit", which might result in underestimates of the overall stroke incidence. Although reliable and validated ${ }^{21}$, functional assessments were performed by telephone, which is less ideal than face-to-face interviews. However, we understand that information bias in our sample is unlikely because our register had a trained nursed who used a validated scale for Rankin assessment by telephone call ${ }^{29}$.

In conclusion, the incidence of first-ever AF-related CE in our setting is lower than in other population-based studies. A third of our sample had previously-known AF. Of those, most had a high risk of embolization $\left(\mathrm{CHA}_{2} \mathrm{DS}_{2} \mathrm{VASc} \geq 3\right.$ ) and a low bleeding risk (HAS-BLED score $<3$ ). A third of AF-related and non-AF-related stroke patients had a poor outcome after three months. These findings might be useful for primary prevention policies. Further studies of $\mathrm{CE}$ ischemic stroke incidence in our setting could clarify the trends we observed.

\section{References}

1. Feigin VL, Lawes CM, Bennett DA, Barker-Collo SL, Parag V. Worldwide stroke incidence and early case fatality reported in 56 population-based studies: a systematic review. Lancet Neurol. 2009;8(4):355-69. https://doi.org/10.1016/S1474-4422(09)70025-0

2. Li L, Yiin GS, Geraghty OC, Schulz UG, Kuker W, Mehta Z et al. Incidence, outcome, risk factors, and long-term prognosis of cryptogenic transient ischaemic attack and ischaemic stroke: a population-based study. Lancet Neurol. 2015;14(9):903-13. https://doi.org/10.1016/S1474-4422(15)00132-5

3. Leyden JM, Kleinig TJ, Newbury J, Castle S, Cranefield J, Anderson CS et al. Adelaide stroke incidence study: declining stroke rates but many preventable cardioembolic strokes. Stroke. 2013;44(5):1226-31. https://doi.org/10.1161/STROKEAHA.113.675140

4. Hajat C, Heuschmann PU, Coshall C, Padayachee S, Chambers J, Rudd AG et al. Incidence of aetiological subtypes of stroke in a multi-ethnic population based study: the South London Stroke Register.J Neurol Neurosurg Psychiatry. 2011;82(5):527-33. https://doi.org/10.1136/jnnp.2010.222919

5. Palm F, Urbanek C, WolfJ, Buggle F, Kleemann T, Hennerici MG et al. Etiology, risk factors and sex differences in ischemic stroke in the Ludwigshafen Stroke Study, a population-based stroke registry. Cerebrovasc Dis. 2012;33(1):69-75. https://doi.org/10.1159/000333417

6. Béjot Y, Ben Salem D, Osseby GV, Couvreur G, Durier J, Marie C et al. Epidemiology of ischemic stroke from atrial fibrillation in Dijon, France, from 1985 to 2006. Neurology. 2009;72(4):346-53.

https://doi.org/10.1212/01.wnl.0000341280.31919.bd

7. Yiin GS, Howard DP, Paul NL, Li L, Mehta Z,

Rothwell PM et al. Recent time trends in incidence, outcome and premorbid treatment of atrial fibrillation-related stroke and other embolic vascular events: a population-based study.J Neurol Neurosurg Psychiatry. 2015;88(1):12-7. https://doi.org/10.1136/jnnp-2015-311947

8. Feigin VL, Krishnamurthi RV, Parmar P, Norrving B, Mensah GA, Bennett DA et al. Update on the global burden of ischemic and hemorrhagic stroke in 1990-2013: the GBD 2013 study. Neuroepidemiology. 2015;45(3):161-76. https://doi.org/10.1159/000441085

9. Strong K, Mathers C, Bonita R. Preventing stroke: saving lives around the world. Lancet Neurol. 2007;6(2):182-7. https://doi.org/10.1016/S1474-4422(07)70031-5

10. Instituto Brasileiro de Geografia e Estatística- IBGE. Censo 2010: resultados. Rio de Janeiro: Instituto Brasileiro de Geografia e Estatística; 2015 [cited 2017 Apr 2]. Available from: http://censo2010.ibge.gov.br/resultados

11. Prefeitura Municipal de Joinville. Lei No 7.448, de 12 de junho de 2013. Insitui o banco de dados Registro de Acidente Vascular Cerebral - AVC de Joinville e dá outras providências. Joinville: Prefeitura Municipal; 2013 [cited 2015 Aug 20]. Available from: https://leismunicipais.com. br/a/sc/j/joinville/lei-ordinaria/2013/745/7448/lei-ordinaria-n-74482013-institui-o-banco-de-dados-registro-de-acidente-vascularcerebral-avc-de-joinville-e-da-outras-providencias 
12. Cabral NL, Gonçalves ARR, Longo AL, Moro CHC,

Costa G, Amaral CH et al. Trends in stroke incidence, mortality and case fatality rates in Joinville, Brazil: 1995-2006.

J Neurol Neurosurg Psychiatry. 2009;80(7):749-54. https://doi.org/10.1136/jnnp.2008.164475

13. Truelsen T, Heuschmann PU, Bonita R, Arjundas G, Dalal P, Damasceno A et al. Standard method for developing stroke registers in low-income and middle-income countries: experiences from a feasibility study of a stepwise approach to stroke surveillance (STEPS Stroke). Lancet Neurol. 2007;6(2):134-9. https://doi.org/10.1016/S1474-4422(06)70686-X

14. Ferro JM. Cardioembolic stroke: an update. Lancet Neurol. 2003;2(3):177-88. https://doi.org/10.1016/S1474-4422(03)00324-7

15. Adams HP Jr, Bendixen BH, Kappelle LJ, Biller J, Love BB, Gordon DL et al. Classification of subtype of acute ischemic stroke. Definitions for use in a multicenter clinical trial. TOAST. Trial of Org 10172 in Acute Stroke Treatment. Stroke. 1993;24(1):35-41. https://doi.org/10.1161/01.STR.24.1.35

16. Oliveira-Filho J, Martins SC, Pontes-Neto OM, Longo A, Evaristo EF, Carvalho JJ et al. Guidelines for acute ischaemic stroke treatment: part I. Arq Neuropsiquiatr. 2012;70(8):621-9. https://doi.org/10.1590/S0004-282X2012000800012

17. Associação Brasileira de Empresas de Pesquisa. http://www.abep.org. [cited 2016 Jan 4].

18. Lip GY, Nieuwlaat R, Pisters R, Lane DA, Crijns HJ. Refining clinical risk stratification for predicting stroke and thromboembolism in atrial fibrillation using a novel risk factor-based approach: the euro heart survey on atrial fibrillation. Chest. 2010;137(2):263-72. https://doi.org/10.1378/chest.09-1584

19. Pisters R, Lane DA, Nieuwlaat R, Vos CB, Crijns HJ, Lip GY. A novel user-friendly score (HAS-BLED) to assess 1-year risk of major bleeding in patients with atrial fibrillation: the Euro Heart Survey. Chest. 2010;138(5):1093-100. https://doi.org/10.1378/chest.10-0134

20. Nice Guidance. Atrial fibrillation: the management of atrial fibrillation. London: Nice; 2006 [cited 2016 Jan 10]. Available from: http://guidanceniceorguk/CG 36; June 2014.
21. Sulter G, Steen C, De Keyser J. Use of the Barthel index and modified Rankin scale in acute stroke trials. Stroke 1999;30(8):1538-41. https://doi.org/10.1161/01.STR.30.8.1538

22. Ahmad OB, Boschi-Pinto C, Lopez AD, Murray CJL, Lozano L, Inoue M. Age standardization of rates: a new WHO standard. Geneva: World Health Organization; 2001.

23. Hannon N, Sheehan O, Kelly L, Marnane M, Merwick A, Moore A et al Stroke associated with atrial fibrillation: incidence and early outcomes in the north Dublin population stroke study. Cerebrovasc Dis. 2009;29(1):43-9. https://doi.org/10.1159/000255973

24. Yiin GS, Howard DP, Paul NL, Li L, Luengo-Fernandez R, Bull LM et al. Age-specific incidence, outcome, cost and projected future burden of atrial fibrillation-related embolic vascular events: a population-based study. Circulation. 2014;130(15):1236-44. https://doi.org/10.1161/CIRCULATIONAHA.114.010942

25. Ogilvie IM, Newton N, Welner SA, Cowell W, Lip GY. Underuse of oral anticoagulants in atrial fibrillation: a systematic review. Am J Med. 2010;123(7):638-45 e4. https://doi.org/10.1016/j.amjmed.2009.11.025

26. Cabral NL, Volpato D, Ogata TR, Ramirez T, Moro C, Gouveia S. Fibrilação atrial crônica, AVC e anticoagulação: sub-uso de warfarina? Arq Neuropsiquiatr. 2004;62(4):1016-21. https://doi.org/10.1590/S0004-282X2004000600016

27. Petty GW, Brown RD Jr, Whisnant JP, Sicks JD, O'Fallon WM, Wiebers DO. Ischemic stroke subtypes a population-based study of functional outcome, survival, and recurrence. Stroke. 2000;31(5):1062-8. https://doi.org/10.1161/01.STR.31.5.1062

28. Lavados PM, Sacks C, Prina L, Escobar A, Tossi C, Araya Fet al. Incidence, case-fatality rate, and prognosis of ischaemic stroke subtypes in a predominantly Hispanic-Mestizo population in Iquique, Chile (PISCIS project): a community-based incidence study. Lancet Neurol. 2007;6(2):140-8. https://doi.org/10.1016/S1474-4422(06)70684-6

29. Baggio, JA, Santos-Pontelli TE, Cougo-Pinto PT, Camilo M, Silva NF, Antunes $P$ et al. Validation of a structured interview for telephone assessment of the modified Rankin Scale in Brazilian stroke patients. Cerebrovasc Dis. 2014;38(4):297-301. https://doi.org/10.1159/000367646 